\title{
A Note on the Mechanism of Cold Air Outbreak
}

\author{
by \\ S. Matsumoto, M. Iida, M. Takenchi, T. Asai and K. Ninomiya \\ Meteorological Research Institute, Tokyo
}

(Received July 9, 1963)

\begin{abstract}
Analyses were made on the synoptic situation over the Far East from Feb. 16 to Feb. 21, 1962, during which minor outbreak of cold air from the continent was observed twice over Japan.

The boundary region between the polar air and the subtropical air was found to be of multiple structure having breaks rather than a single substantial boundary layer separating two air masses.
\end{abstract}

\section{Introduction}

The outbreak mechanism of cold air from polar region has long been calling attentions among both of theoretical and synoptic meteorologists (e.g. SYono, 1948; Rossby, 1949 ; Palmén, 1949; Palmén and Nagler, 1949; Palmén and Newton, 1951 etc.), since it is undoubtedly one of the most important aspects of general circulation. The cold air generated in the polar cap occasionally spreads out towards southern area (sometimes in a form of cut-off cold vortex) and it necessarily sinks, resulting in the release of potential energy as well as the meridional exchange of heat and vorticity etc.

Classical studies were based upon discontinuous models, and analyses also verified the existence of sharp discontinuous boundary layer between polar and tropical air masses. According to PALMÉN and others $(1949,1951)$ the polar air mass is surrounded continuously by the polar front, accompanying families of cyclones along its outer skirt, which meanders and sometimes spreads out southwards or cuts off the cold air from the source region. The frontal layer is analysed throughout those processes.

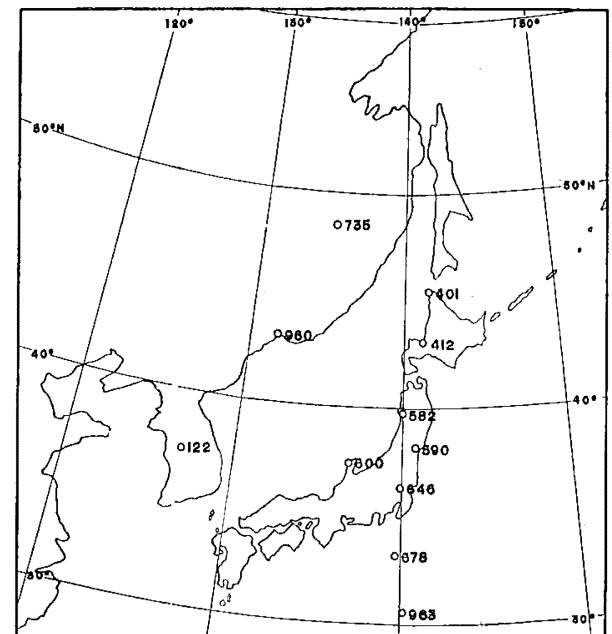

Fig. 1. Location and station number of the stations used for the cross section analyses. 
However, such a concentrated frontal layer as is shown by PALmén is rather seldom observed over the Far East, probably because of the complexity in the baroclinic field. Usually it is very difficult to identify those frontal systems. A case will be shown, in this paper, in which the cold air is not bounded by a single frontal layer but by a system of discontinued frontal layers.

Subsiding cold air yields a release of potential energy which is required to maintain the kinetic energy of the general circulation. On the other hand, recent studies of general circulation have revealed the existence of indirect meridional circulation in middle latitudes which counteracts against the northward heat transport so as to keep the meridional temperature contrast. Meanwhile, an individual indirect circulation might serve to strengthen a local temperature concentration in those latitudes at the expense of kinetic energy. A characteristic example of this type, the case of Feb. 16-20, 1962*, will be discussed hereafter.

Fig. 1 shows the location of stations appearing in the following analyses with their station numbers.

\section{Synoptic situation}

In the following a brief description of the synoptic situation between 16 and 20 Feb. 1962 will be given. A pretty large scale of cold vortices are observed in the upper atmosphere over Greenland and Okhotsk Sea separately and minor troughs are travelling eastwards successively around the cold vortex to the north. In the lower atmosphere, outburst of cold air in a form of north-westerly monsoon is observed over Japan Sea on 16 and on 19 Feb. right after the passage of upper minor troughs, although the intensity of monsoon is not so strong compared to the typical outbursts.

Figs. $2 \mathrm{a}$ and $2 \mathrm{~b}$ show $500 \mathrm{mb}$ and surface weather chart respectively of $21 \mathrm{I}$, Feb. 17. On $500 \mathrm{mb}$ level, a closed isotherm of $-42^{\circ} \mathrm{C}$ is located over the east coast of Siberia and a jet stream is found around the southern peripherie of this cold dome and another jet stream is observed further to the south. Both of the strong wind system are obviously associated with zones of temperature concentration which are related to "polar front" and "subtropical front" respectively (see also Fig. 3). The southern jet system can be traced back to farther west but the northern one seems to be disconnected. On the lower troposphere, cyclones generated over northern Korea are now shifted to Japan Sea area and deepened considerably.

A series of vertical cross sections are analysed along $140^{\circ} \mathrm{E}$ meridian from Wakkanai (47-401) to Torishima (47-963) and an example is given in Fig. 3. It is clearly seen that double jet system mentioned above is closely connected with frontal system in the mid-troposphere. The southern frontal layer bearing principal temperature contrast on this map time is continued to the subtropical tropopause and,

\footnotetext{
* During this period, preliminary special observations were made in Hokuriku District (Japan Sea coastal region of the central part of Japan Islands) under the heavy snow storm project.
} 


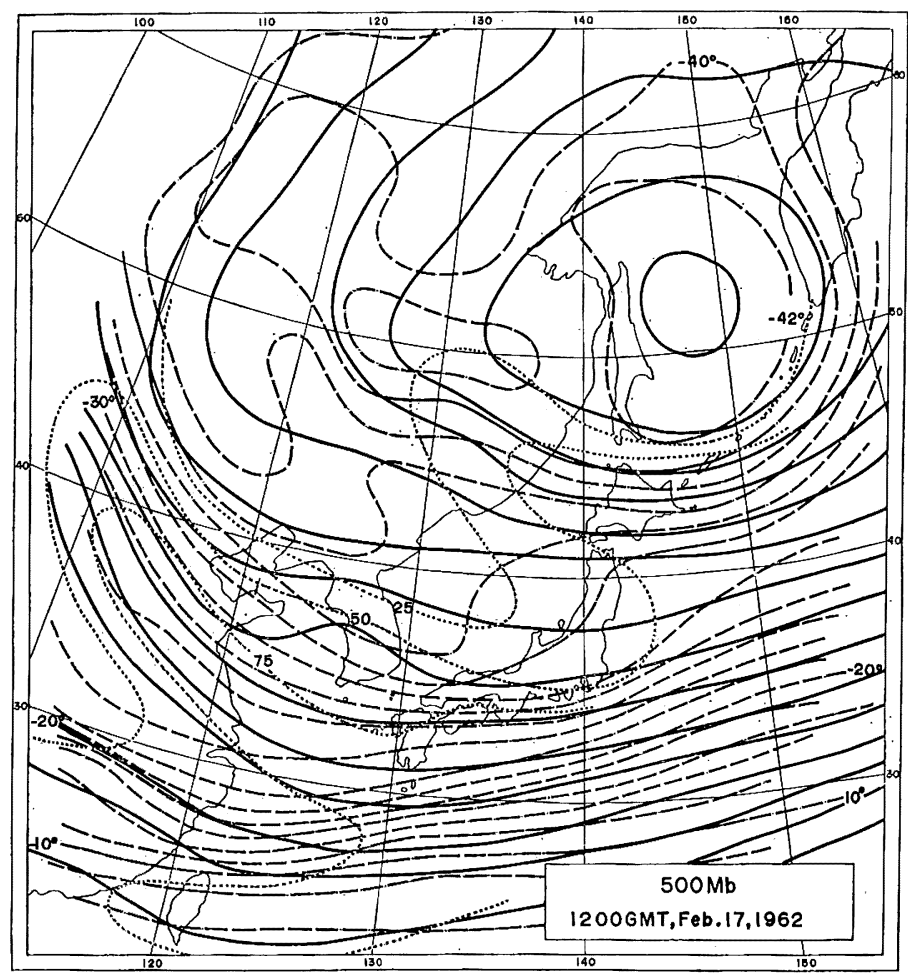

Fig. 2 a. The 500-mb chart for $21 \mathrm{I}$ Feb. 17, 1962, showing contours (solid lines), isotherms (dashed lines labeled in ${ }^{\circ} \mathrm{C}$ ) and isotachs (dotted lines labeled in knots).

Fig. 2 b. The surface chart for 21 I Feb. 17, 1962.

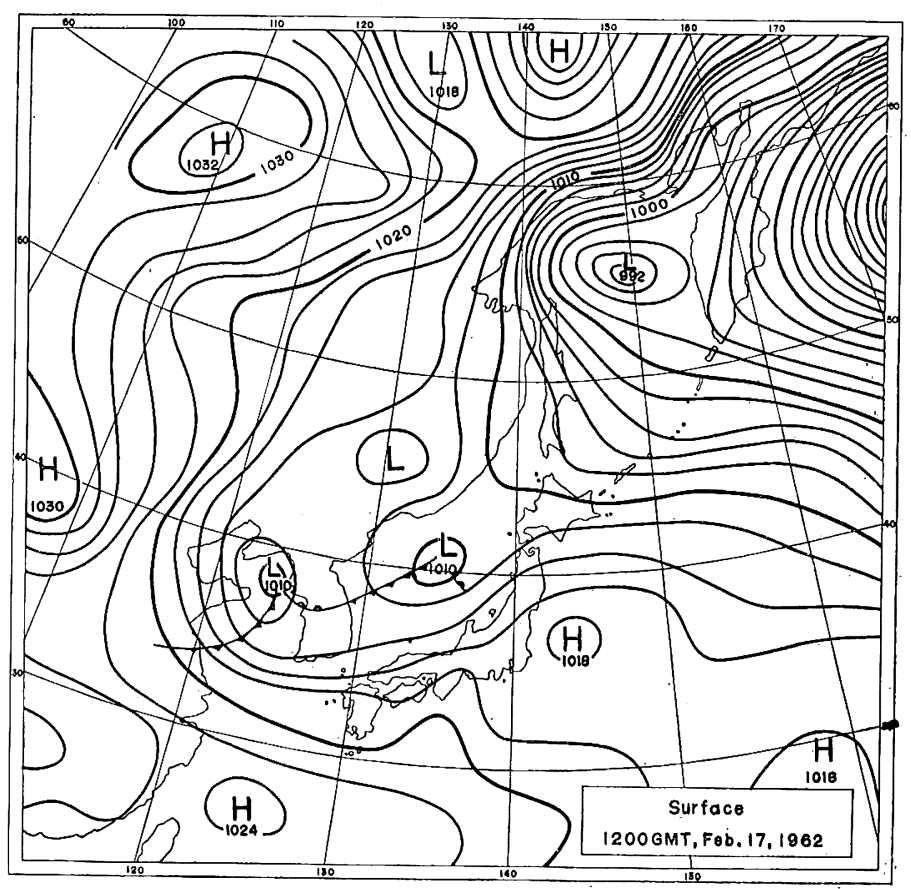



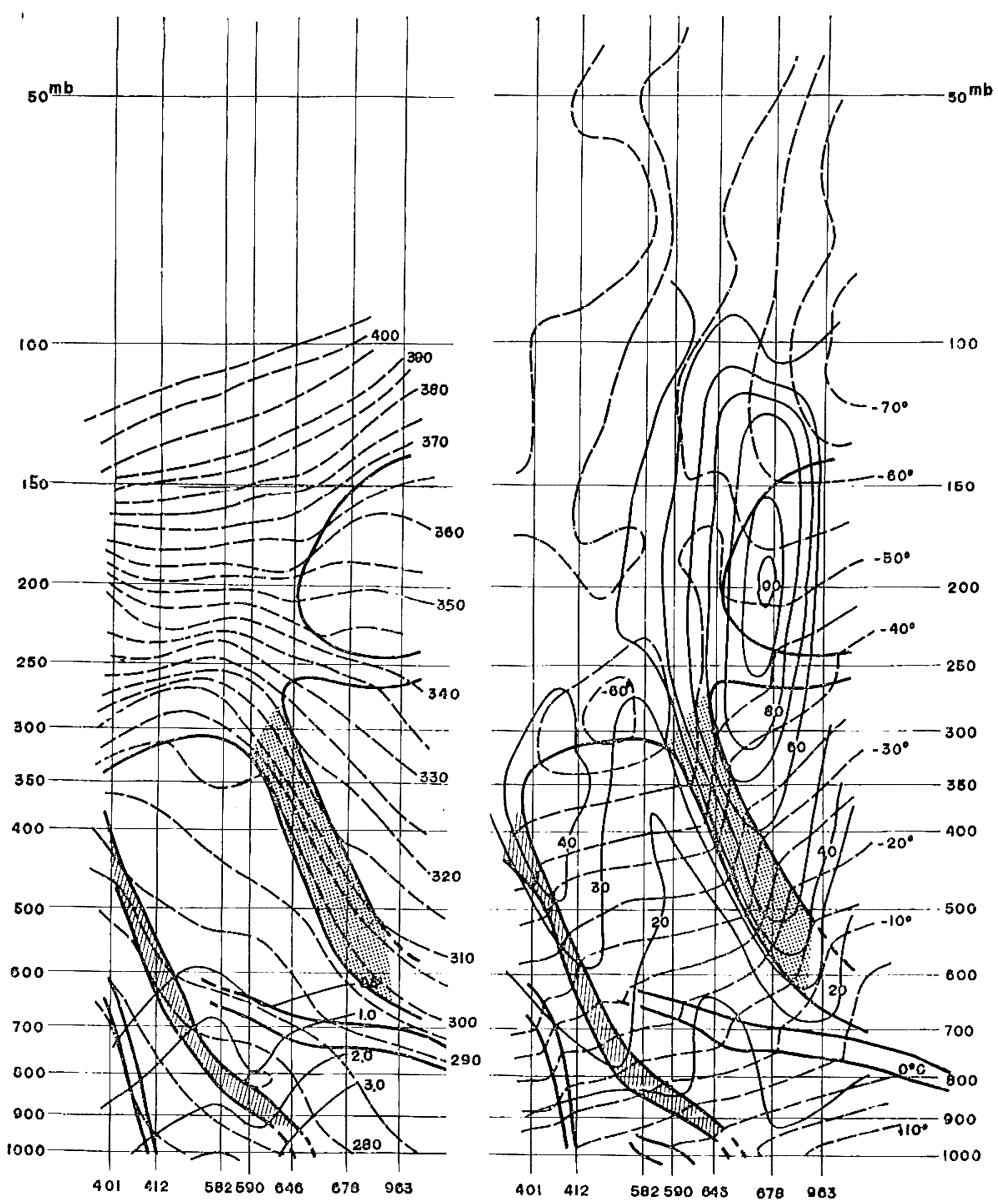

Fig. 3. Meridional cross sections at 21 I Feb. 17, 1962. Right figure: the thin solid lines give the wind velocity $\left(\mathrm{m} \mathrm{sec}^{-1}\right)$, the dashed lines are isotherms and the heavy lines are tropopauses or boundaries of frontal layers dashed where they are not very well marked. Left figure: the thin solid lines give the specific humidity $\left(\mathrm{gr} \mathrm{kgr}^{-1}\right)$ and the dashed lines the potential temperature $\left({ }^{\circ} \mathrm{K}\right)$. Tropopauses and frontal layers are also entered.

therefore, will be called "subtropical front" in the following discussions. The northern frontal layer, on the other hand, had borne a principal role in the previous map times and was continued to the polar tropopause which now located outside of our cross section. Let us denote the latter frontal system as "polar front" conventionally. These two frontal layers are quite remarkable in the middle troposphere. However, in the lower troposphere they are hardly discernible and it is usually quite difficult to identify in relation to surface frontal system. Furthermore we can analyse some more frontal systems in the lowermost part of the atmosphere, one in the north which is always found in the polar air mass and may be called "polar inversion layer" and the other in southern area which lies nearly horizontally 
in the layer from about $600 \mathrm{mb}$ to $800 \mathrm{mb}$ and is characterized by the humidity drop above this layer quite similar to the "trade wind inversion".

\section{Analyses by means of serial cross sections}

To demonstrate the characteristic feature of exchange mechanism during our period, successive configurations of frontal systems together with tropopauses are shown in Fig. 4 schematically from 09 I 16 th to 21 I 19th. Here, tropopauses are shown by chain lines and "polar front", "subtropical front", "polar inversion layer" and "trade wind inversion layer" as are defined in the previous section are shown by hatched, stippled, painted and unpainted double lines respectively. Air masses bounded by those frontal layers are indicated by $\mathrm{P}, \mathrm{P}$, $\mathrm{P}$ " and $\mathrm{T}$ showing polar air mass, modified polar air masses and tropical air mass respectively. It should be noted that this classification is not necessarily the same as in the classical air mass theory but is used for the sake of convenience.

It is seen from this figure that the frontal systems are shifting northward continuously despite of the southward cold air outburst. The situation of 21 I 18th is quite similar to that of $09 \mathrm{I} 16 \mathrm{th}$, and the "subtropical front" is taking the role of

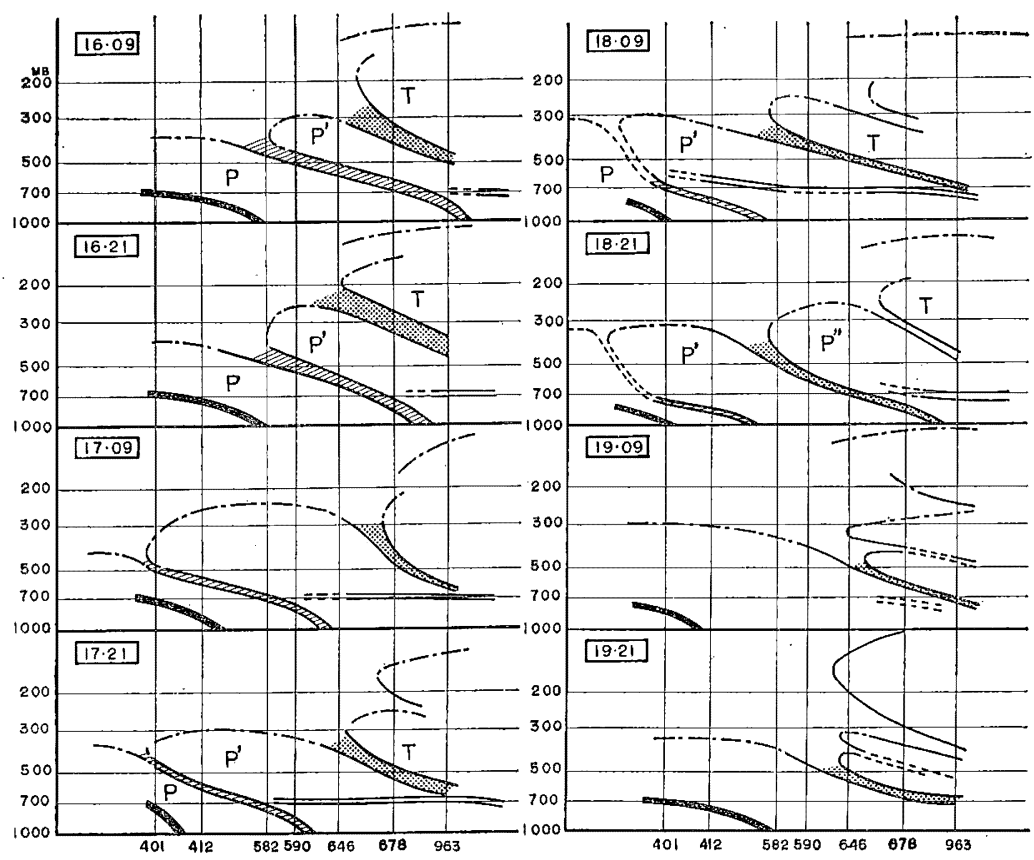

Fig. 4. Schematic configuration of tropopauses and frontal layers from 09 I Feb. 16 to 21 I Feb. 19, 1962. Tropopauses are indicated by chain lines, "subtropical front" by stippled double lines, "polar front" by hatched double lines, "polar inversion layer" by painted double lines and "trade wind inversion layer" by unpainted double lines. Characters P, P', P" and T are entered to identify air masses. 
the former "polar front" and the original "polar front" is disappearing by losing temperature contrast. Cold air mass creating a principal temperature contrast is now $\mathrm{P}^{\prime}$ instead of $\mathrm{P}$.

Displacements of boundary layer presumed from successive vertical cross sections do not necessarily coincide with the substantial movement of air mass. If a concentrated boundary layer were to surround the polar air mass with flower-like deformation as was suggested by PALMÉN (1949) and if it were either to circulate around the pole or to amplify in accordance with southward outbreak, frontal layers in a cross section should move back and forth or at least shift southward. Actually, however, they continuously move northward, even though minor troughs passed successively and outbreaks followed as was pointed out before.

The northward shifts of frontal layers are also verified by using horizontal time sections. Meridional temperature distribution along $140^{\circ} \mathrm{E}$ meridian is shown as a function of time in Fig. 5 for each levels. Looking at for example $500 \mathrm{mb}$ time section (Fig. $5 \mathrm{~b}$ ), we find that zones of concentrated isotherms, one in the northern part and the other in the southern part, move northward. As to the temperature field itself, southward invasion of cold air occurs on 16th and 19th corresponding to the transit of trough. It is also noted that a secondary temperature fall is observed

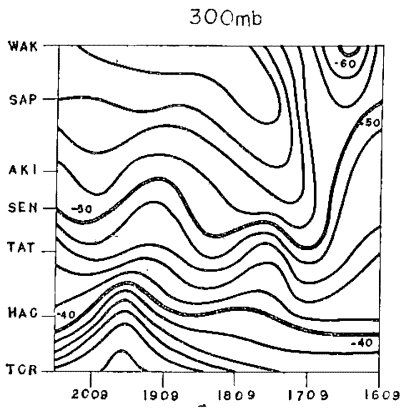

(a)

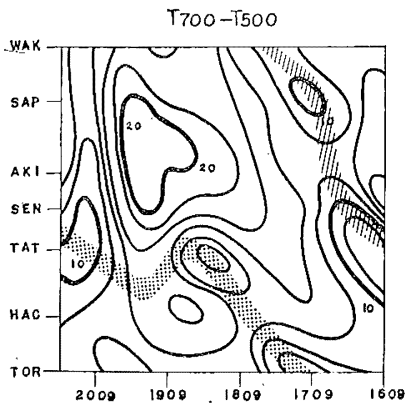

(d)

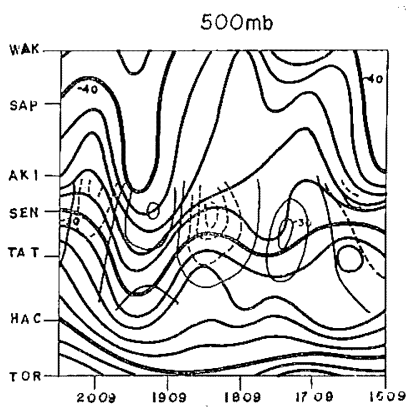

(b)

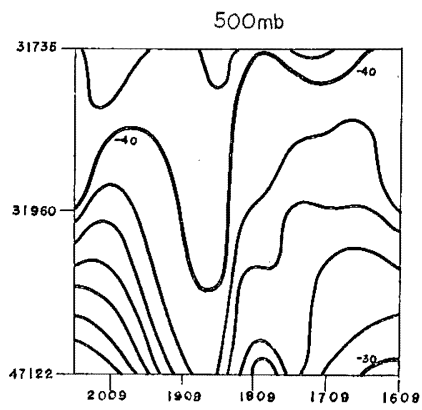

(e)

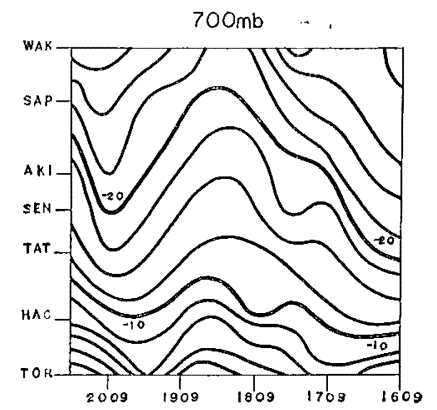

(c)

Fig. 5. Time sections indicating meridional distribution of temperature on $300 \mathrm{mb}$ (a), $500 \mathrm{mb}$ (b) and $700 \mathrm{mb}$ (c) and of temperature difference between $700 \mathrm{mb}$ and $500 \mathrm{mb}$ level along $140^{\circ} \mathrm{E}$ meridian $500 \mathrm{mb}$ temperature distribution along the east coast of the continent is also given (d). Abscissa is date and time in Japan local time. On Fig. $5 \mathrm{~b}$ the vertical motion is also entered by thinner lines in every $20 \mathrm{mb} \mathrm{hr}^{-1}$ (broken for downward motion). 
on 18 th when the reference area is in a ridge situation which will be discussed later.

The locations of frontal layers are more easily discriminated by taking the static stability into account. Fig. $5 \mathrm{~d}$ shows the same kind time section of temperature difference between $500 \mathrm{mb}$ and $700 \mathrm{mb}$ level, smaller value of which corresponds to stabler layer. The axes of minimum value are indicated on this figure by the same symbols, hatches and stipples, as are used to identify "polar front" and "subtropical front" respectively. Northward shift of frontal system will thus be clearly observed.

The time section of temperature distribution along western coastal region of

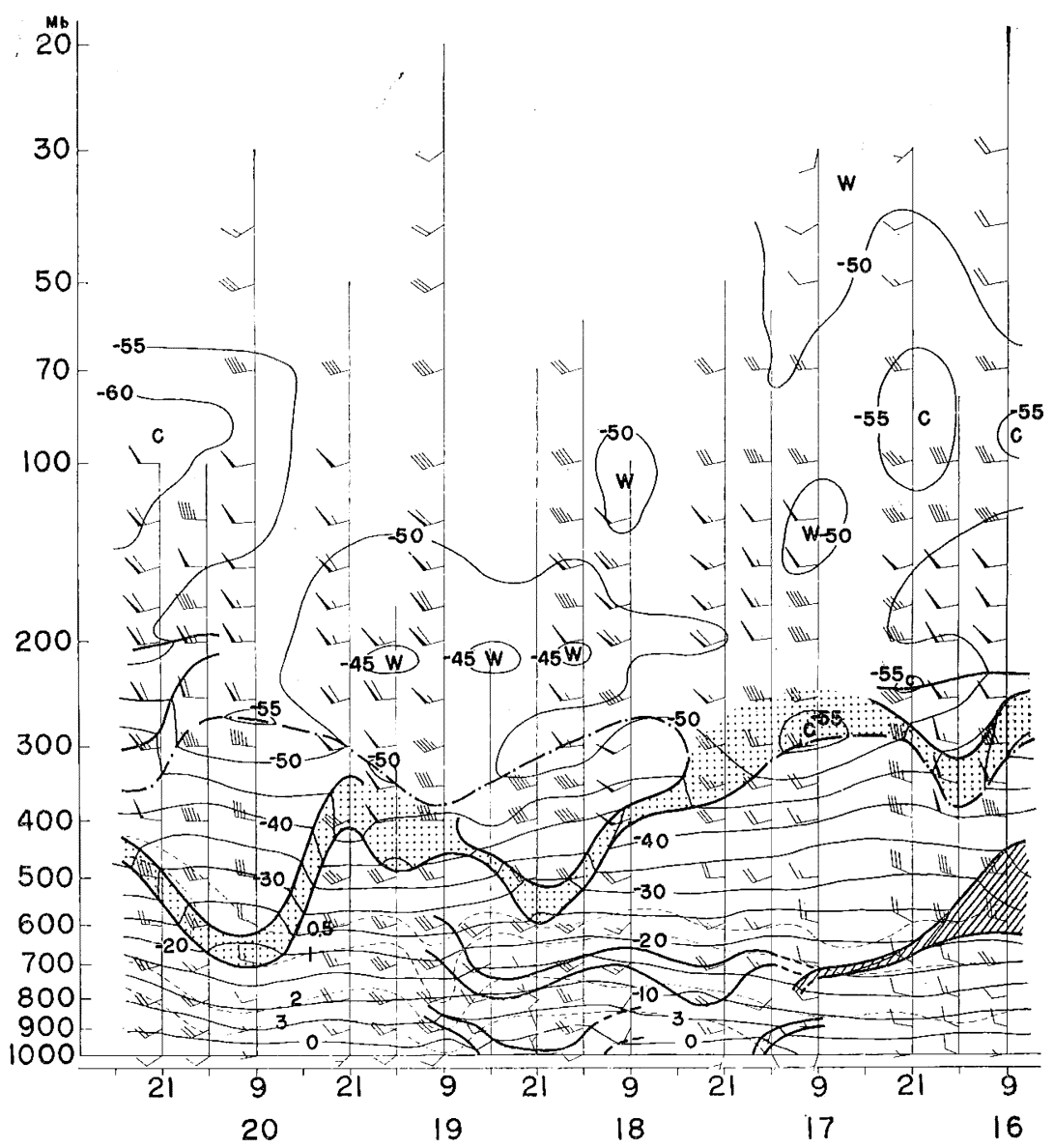

Fig. 6. Vertical time section at Wajima (47-600) from 09 I Feb. 16 to 21 I Feb. 20. Thin solid lines give isotherm labeled in ${ }^{\circ} \mathrm{C}$, heavy solid lines indicate boundaries of frontal layer (stipples and hatches are used in a same manner as in Fig. 4), chain lines indicate tropopauses and dashed lines give specific humidity labeled in $\mathrm{gr} \mathrm{kgr}^{-1}$. Half barbs, full barbs and shaded-in wedges indicate wind speeds of $5 \mathrm{~m} \mathrm{sec}-1,10 \mathrm{~m}$ $\mathrm{sec}^{-1}$ and $50 \mathrm{~m} \mathrm{sec}^{-1}$ respectively. 
Japan Sea located roughly 10 degrees to the west of $140^{\circ} \mathrm{E}$ meridian is also shown in Fig. $5 \mathrm{e}$ for the sake of reference. Comparing Fig. $5 \mathrm{~b}$ and Fig. $5 \mathrm{e}$ we can find a considerably similar distribution except the lag of about one day and it might said that the configuration appearing on those time sections can be replaced by the spacial distribution as a first approximation. Various kind of modifications onto the system such as air-sea interaction over Japan Sea will be left for the future discussions.

An example of vertical time section is given in Fig. 6. Station Wajima (47600 ) is chosen here for reference because the data of 6 hourly observations are available during our period. Here again "polar front" and "subtropical front" are indicated by hatched and stippled zones respectively, and the gradual tendency of lowering heights reveals the fact that both of the frontal system are receding towards north. Cold domes are found on 16th and 19th, the former being bounded by "polar front" and the latter by "subtropical front" which may be redefined as actual polar front. In the lowermost part of the atmosphere, the "polar front" is discontinued and other frontal system related to the surface depression is analysed because it is rather unreasonable to identify them from the point of view of stratification and potential temperature above and below.

\section{Structure and mechanism concerning cold air out- break}

Fig. 7 shows $500 \mathrm{mb}$ chart of 09I 19th. $500 \mathrm{mb}$ height and temperature difference between $500 \mathrm{mb}$ and $700 \mathrm{mb}$ level are given by full line and broken line labeled in ${ }^{\circ} \mathrm{C}$ respectively. Small values of temperature lapse indicate stable layer. We find two zones of small value, one lying over Hokkaido and the other along southern coast of Japan Islands. On this figure, successive positions of those stable layers from 09 I 17 th to 21I 18th are also entered over Japan and her neighbourhood by applying the same symbols as was used in the previous section. (Those regions coincide farely well with the zones of maximum horizontal temperature concentration). It is again confirmed that both of the "polar front" and the

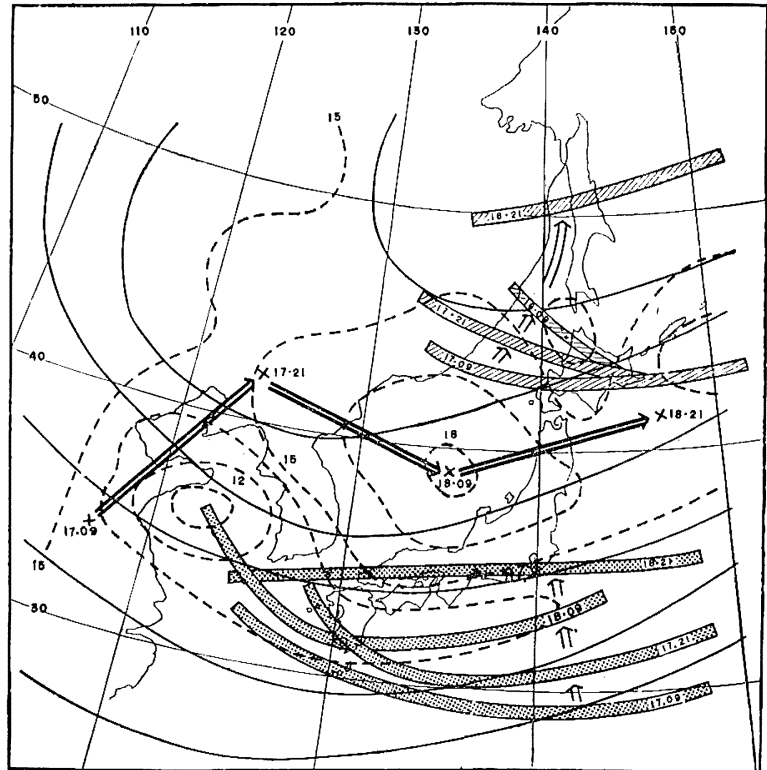

Fig. 7. Composite $500 \mathrm{mb}$ chart. Full lines give $500 \mathrm{mb}$ contours and dashed lines the temperature difference between $700 \mathrm{mb}$ and $500 \mathrm{mb}$ labeled in ${ }^{\circ} \mathrm{C}$ for 09 I Feb. 18, 1962. Successive positions of "polar front" and "subtropical front" are indicated by hatched and stippled strips respectively from 09 I Feb. 17 to $21 \mathrm{I}$ Feb. 18. Displacement of unstable air is shown by heavy arrows connecting $\times$ symbols labeled with date. 
"subtropical front" are displacing northward in accordance with the approach of the trough from west.

Large values of temperature lapse rate, on the other hand, indicate unstable stratification, and are found in the region between two frontal systems. At 09 I 18th a pretty unstable air is found over the middle of Japan Sea. Successive position of this unstable air is shown by symbol labeled with date and displacement during $12 \mathrm{hr}$. period is shown by heavy double line, which shows eastward movement with a velocity similar to that of the whole system. The fact that the development and movement of the surface cyclone coincide with this unstable air suggests the existence of convergence and upward motion. As is well known, a convergence has a destabilizing effect and upward motion may result in cooling in the upper troposphere. It might be more reasonable to explain the cyclone formation and development from the dynamical point of view, i.e. instability rather than from the classical frontal theory.

Vertical motion is computed for this particular synoptic case by Matsumoto, Asar and Ninomiya (1963) and the result is reproduced on Fig. 5 b. A remarkable fact is that a colder air is accompanied by upward motion and vice versa. Thus resulting negative correlation between the temperature and the vertical velocity suggests an energy transformation from kinetic to potential energy contrary to the ordinary process such as considered on cold air outbreak. In other words, cold air is not always advected from the source region but sometimes can be generated or intensified by vertical motion, and as a result, the horizontal temperature contrast which has been considered to constitute the air mass boundary is intensified so as to increase the potential energy.

Finally we obtain the model such as shown in Fig. 8 schematically. Representative isotherms on $500 \mathrm{mb}$ level and $700 \mathrm{mb}$ level are shown by full lines and broken lines respectively. An area surrounded by chain line entered in the ridge region shows the development of subtropical tropopause under which the upper tropospheric air is cooled. The frontal systems are indicated by the same symbols as were used in the discussions above, showing that they are found around the southern peripherie of successive cold domes in the trough regions. The characteristic feature of this particular synoptic situation is that the frontal layer does not exist continuously but there is a break between northern polar air and southern tropical air. Isotachs on $500 \mathrm{mb}$ level are also entered by dotted lines indicating the double jet system which corresponds to the multiple structure in the frontal system.

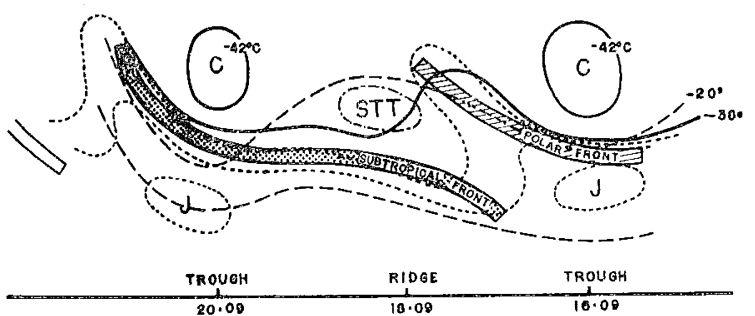

Fig. 8. Schematic model showing cold air outbreaks obtained by space and time serial analyses. Full lines show isotherms on $500 \mathrm{mb}$ level, dashed lines those on $700 \mathrm{mb}$ level and dotted lines isotachs in midtroposphere. The area STT encircled by a chain line indicates a remarkable develpment of subtropical tropopause. 


\section{Conclusion}

Informations obtained in this study suggest somewhat different structure and mechanism in the behavior of cold air outbreak from those proposed in classical studies. Although the case studied here may be of rather finer structure in a very large cut-off cold vortex, the importance should be emphasised in the fact that the frontal system separating the polar air from the tropical air has a multiple structure with breaks and the principal temperature contrast seems to be generated sporadically by indirect circulations.

The terminology "front" appearing in this paper is not necessarily used to define a sharp boundary layer as was defined in the classical frontal theory but is sometimes used to indicate a zone of concentrated baroclinic field. Probably because of the complexity in the baroclinic field, it is rather seldom over the Far Eastern area that we can analyse a single characteristic frontal layer such as appearing in text books. This fact would suggest an appropriateness of continuous atmospheric model upon which progresses in numerical weather prediction technique and other fields of dynamic meteorology are based. The recent studies have revealed the fact that the principal procedure of exchange mechanism in middle latitudes is the meridional transport due to baroclinic unstable waves rather than sporadic outflow of cold air as was advocated in classical discontinuous atmospheric models.

Acknowledgments — The writers wish to thank Dr. H. ARAkAwA for his stimulations and Mr. T. Rikitake for his discussions. We are also greatly indebted to Miss T. Akiyama and Miss H. Imai for their valuable assistance in the preparation of cross sections.

\section{References}

Matsumoto, S., T. Asai and K. Ninomixa, 1963: Heat and water-vapor budget in large and small scale in winter over the middle of Japan Islands, to be published.

PALMÉN, E., 1949: On the origin and structure of high-level cyclones south of the maximum westerlies, Tellus, 1, 22-31.

PATḾ́N, E. and K. M. NAGLER, 1949: The formation and structure of a large scale disturbance in the westerlies, Jour. Meteor., 6, 227-242.

Paumén, E. and C. W. Newton, 1951: On the three-dimensional motions in an outbreak of polar air, Jour. Meteor, 8, 25-39.

Rosssy, C.-G., 1949: On a mechanism for the release of potential energy in the atmosphere, Jour. Meteor., 6, 163-185.

Syōno, S., 1948: On a mechanism for the cold air outbreak (in Japanese), Jour. Met. Soc. Japan, 26, Special Report, 1-7. 


\title{
寒波吹出しの機構について
}

\author{
松本誠一・似昍睦治郎・竹内衛夫 \\ 浅非冨雄・二窝洸三
}

北陸不速続線予備钼測が行なわれた 1962 年 2 月 16 日から 2 月 21 日至る期間の, 極東区域彷ける 綜観的解析を行なった。この期間中弱い北東季節風の吹出しが 2 回抗こっている。

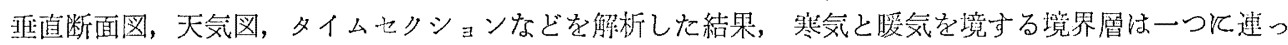

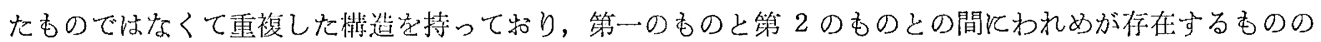
よろであり，従来指摘されている寒気欣出しのモデルとかなり異なった啃造を持っていたことが示される。 